\title{
Incomplete Circle of Willis: A Possible Triggering Factor for Migraine
}

Tamamlanmamış Willis Poligonu: Görsel Auralı Migren için Olası Tetikleyici Faktör

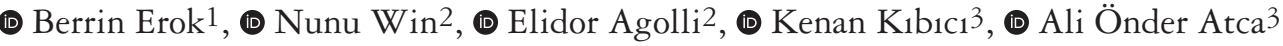 \\ 1 University of Health Sciences Turkey, Prof. Dr. Cemil Tascioglu City Hospital, Clinic of Radiology, Istanbul, Turkey \\ 2Medicana Bahcelievler Hospital, Clinic of Radiology, Istanbul, Turkey \\ ${ }^{3}$ Altinbas University Faculty of Medicine, Bahcelievler Medical Park Hospital, Clinic of Radiology, Istanbul, Turkey
}

Keywords: Fetal origin of posterior cerebral artery, circle of Willis, migraine, visual aura

Anahtar Kelimeler: Fetal orijinli posterior serebral arter, Willis poligonu, migren, görsel aura

\section{Dear Editor;}

The Circle of Willis (CoW) is an anastomotic arterial heptagon which is located at the inferior surface of the brain, within the interpedincular cistern. It is formed by the anteriorly located internal carotid arterial system and the posteriorly located vertebrobasilar arterial (BA) system and provides an important collateral pathway to maintain sufficient cerebral perfusion. However, based on the complexity of the embryological development, there are numerious individual anatomical variations. Herein, we report an uncommon association of cerebral arterial aberrations; incomplete CoW posteriorly and a bihemispheric anterior cerebral artery (ACA) anteriorly in a 21 year old male patient with a family history of cerebral arterial aneurysms who was admitted to our hospital with the complaint of a five-year history of migraine headaches often accompanied by visual auras such as flashes of the light or blind spots, which were triggered with heavy working or sleep and caffeine deprivation. Magnetic resonance angiograhy revealed no aneurysm formation, but uncommon associations of multiple CoW variations were demonstrated. Posteriorly, a right complete (full) type fetal posterior cerebral artery with aplasic P1 segment and hypoplasic posterior communicating artery (PCoA) was present. However, this PCoA was unusually bifurcating with two termination points; one was the classical anastomose with the P2 segment and the second was an atypical anastomose with the BA at its termination (Figure 1a). Although it seemed to complete the circle to some extent, the connecting segment was hypoplasic. Such a different termination pattern was described as type II termination by Gunnal et al. (1). However, it was defined for a single PCoA terminating at the tip of the BA, unlike the bifurcated PCoA having both typical (type I) and an atypical termination in our patient. This PCoA can not be defined as duplication due to the lack of two seperate origins or can not be defined as fenestration due to the lack of eventual distal rejoining. To our knowledge, such a different morphological variation of PCoA has not been described. The second variation in the posterior circulation was the absence of left PCoA (Figure 1a). Due to the absence of right P1 and left PCoA, the posterior CoW was incomplete bilaterally. The last variation was bihemispheric ACA, a rare variant of the anterior circulation, in which the A2 segment of the right ACA that terminated early in its course was hypoplasic and the left dominat A2 segment of the ACA bifurcated into the bilateral pericallosal arteries to supply both of the hemispheres (Figure 1a, b).

During the embryological development of cerebral arteries, a complex process involving regressions and anastomoses of the primitive vessels take place, and may result in wide range of individual variations from normal anatomy, including persistant fetal forms, hypoplasia or aplasia of the arterial segments, duplications or fenestrations of the arteries or persistent carotidbasilar anastomoses. Although most of them are detected incidentaly, they can also be of significant clinical value by their association with increased risk of aneurysm development. In addition, incomplete CoW with absent or hypoplasic segments has been recognized as associated with migraine headcahes occuring especially with visual auras by affecting the cerebral

Address for Correspondence/Yazışma Adresi: Berrin Erok MD, University of Health Sciences Turkey, Prof. Dr. Cemil Tascioglu City Hospital, Clinic of Radiology, Istanbul, Turkey Phone: +90 5302604150 E-mail: drberrinerok@hotmail.com ORCID: orcid.org/0000-0001-8036-547X

Received/Geliş Tarihi: 26.12.2020 Accepted/Kabul Tarihi: 23.01 .2022

${ }^{\circ}$ Copyright 2022 by Turkish Neurological Society

Turkish Journal of Neurology published by Galenos Publishing House. 

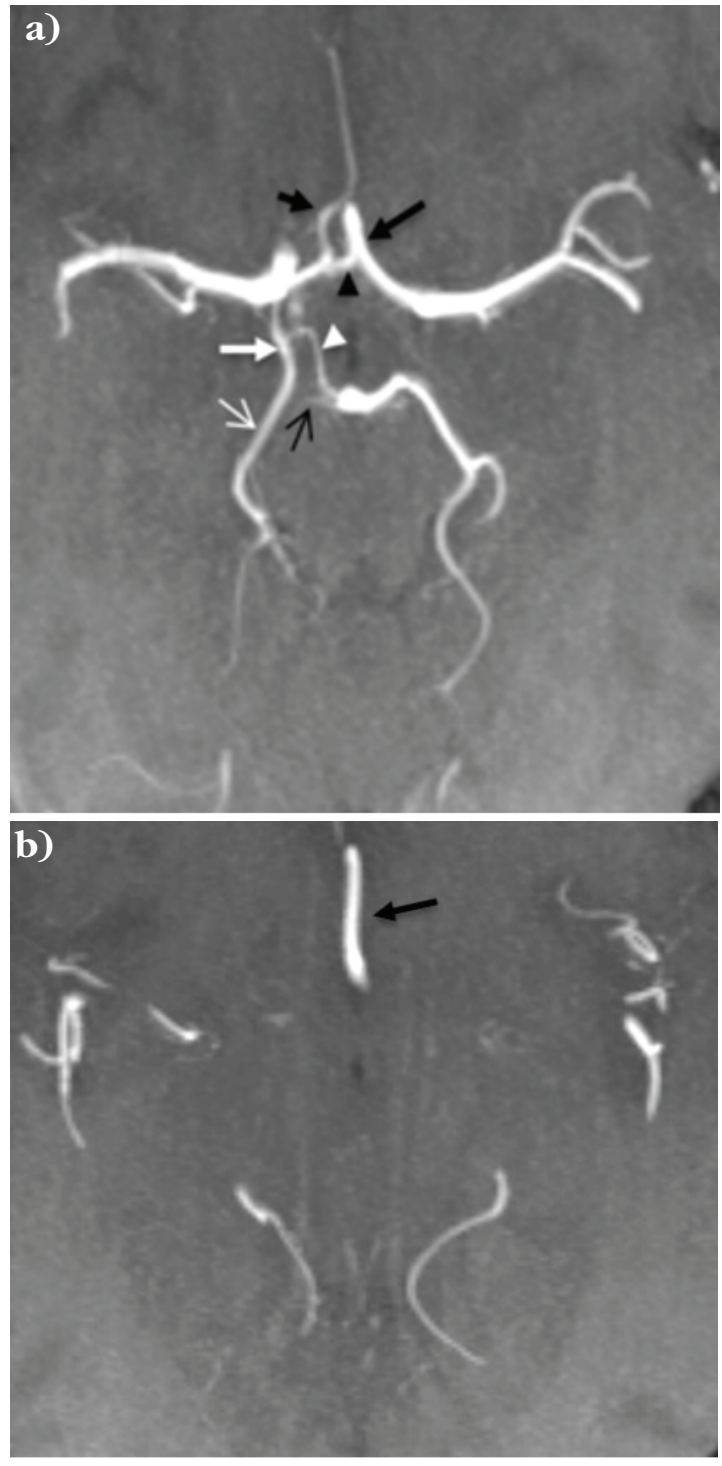

Figure 1. Maximum intensity projection images from magnetic resonance angiography demonstrating the right complete (full) type fetal posterior cerebral artery (fPCA), the aplastic left posterior communicating artery $(\mathrm{PCoA})$ and the left bihemispheric anterior cerebral artery ACA. a) The P2 segment of the right PCA (thin white arrow) appearing as the continuation of the PCoA which is unusually bifurcating with two termination points; one is the classical anastomose with the PCA (a; thick white arrow) and the second is an atypical anastomose with the basilar arterial at its termination (a; white arrow head). The P1 segment is absent and the thin black arrow shows the right SCA. The left PCoA is absent. a, b) The left dominant bihemispheric A2 segment that supplies bilateral ACA territories ( $\mathrm{a}, \mathrm{b}$; thick black arrows) and a contralateral nondominant A2 segment (a; short black arrow) are shown blood adaptation when there is increased metabolic demands, particularly when it is in the posterior part of the CoW $(2,3,4)$. The effect of CoW variations on compensatory capacity varies and not all decreases cerebral blood flow (CBF) compensation significantly. Only the co-occurance of bilaterally absent connecting segments that is P1 and/or PCoM or A1 and/or ACoM prevents blood flow adaptation obviously, which is a very rare occurance as in our patient (5). Although co-incidental occurance of the migraine could not be excluded, we thought that the migraine headaches might be triggered by transient decreases in CBF due to the presence of the incomplete posterior CoW. Unfortunately, we did not measure regional CBF during increased brain activity in our patient to demonstrate significantly decreased cerebral perfusion and the relationship with migraine headaches and visual auras. On the other hand, this possibilty may also be associated with increased risk of stroke particularly in advanced ages. Therefore, being aware of these aberrations is important for an accurate evaluation and management of the iscemic areas in the setting of stroke especially when the unexpected involvements of arterial territories are present. Moreover, such variations should always be considered and evaluated before endovascular/neurosurgical interventions to prevent complications.

\section{Ethics}

Informed Consent: Informed consent was obtained.

Peer-review: Externally peer-reviewed.

\section{Authorship Contributions}

Surgical and Medical Practices: B.E., N.W., E.A., Concept: B.E., N.W., Design: B.E., E.A., A.Ö.A., Data Collection or Processing: B.E., Analysis or Interpretation: B.E., N.W., K.K., A.Ö.A., Literature Search: B.E., Writing: B.E.

Conflict of Interest: No conflict of interest was declared by the authors.

Financial Disclosure: The authors declared that this study received no financial support.

\section{References}

1. Gunnal SA, Farooqui MS, Wabale RN. Anatomical variability of the posterior communicating artery. Asian J Neurosurg 2018;13:363-369.

2. Cucchiara B, Wolf RL, Nagae L, et al. Migraine with aura is associated with an incomplete circle of Willis: Results of a prospective observational study. PLoS One 2013;8:e71007.

3. Bugnicourt JM, Garcia PY, Peltier J, et al. Incomplete posterior Circle of Willis: a risk factor for migraine? Headache 2009;49:879-886.

4. Cavestro C, Richetta L, L'Episcopo MR, et al. Anatomical variants of the Circle of Willis and brain lesions in migraineurs. Can J Neurol Sci 2011;38:494-499.

5. Zhou H, Sun J, Ji X, et al. Correlation between the integrity of the Circle of Willis and the severity of initial noncardiac cerebral infarction and clinical prognosis. Medicine (Baltimore) 2016;95:e2892. 